\title{
MEDICINAL EFFICACY OF ANTIHYPERTENSIVE AGENTS FOR ACUTE INFLAMMATION; AN ASSOCIATED RISK FACTOR OF HYPERTENSION
}

\author{
Muhammad Salman Sarwar ${ }^{1}$, Zinayyera Subhani2*, Muhammad Bilal ${ }^{2}$, Qura- tul-Ain Nazir ${ }^{3}$ \\ ${ }^{1}$ Institute of Molecular Biology and Biotechnology, University of Lahore, Lahore, Pakistan \\ ${ }^{2}$ Department of Biochemistry, University of Agriculture, Faisalabad, Pakistan \\ ${ }^{3}$ University of Veterinary and Animal Sciences, Lahore, Pakistan \\ Corresponding author email: zainisub@gmail.com
}

This is an open access article distributed under the Creative Commons Attribution License, which permits unrestricted use, distribution, and reproduction in any medium, provided the original work is properly cited.

\begin{tabular}{|c|c|}
\hline ARTICLE DETAILS & ABSTRACT \\
\hline Article history: & Hypertension is a lasting therapeutic complaint which can be kept in control by changing one's dietary and lifestyle \\
\hline Received 12 August 2017 & habits. Present study is based on identification of risk of acute pancreatitis which may occur with different doses of \\
\hline Accepted 12 September 2017 & tudy population was administered with $\beta$-blockers. The $\beta$ - \\
\hline Available online 26 October 2017 & $\begin{array}{l}\text { blockers significantly decreased the levels of CRP (C- Reactive Protein) of test population. This observation strongly } \\
\text { depicts high potential of beta blockers in stabilization of CRP levels and decreasing inflammatory response. In our }\end{array}$ \\
\hline Keywords: & $\begin{array}{l}\text { study the patients were administered with many combinations with beta-blocker and their results showed that these } \\
\text { combinations lower the CRP level in hypertensive patients. We conclude that antihypertensive also minimize the }\end{array}$ \\
\hline $\begin{array}{l}\text { anti-inflammatory, acute pancreatitis, } \beta \text { - } \\
\text { blocker, C- reactive protein, } \\
\text { hypertension }\end{array}$ & $\begin{array}{l}\text { inflammation associated hypertension but not completely, as inflammation was reversed only in } 67.5 \% \text { population } \\
\text { who were using beta-blocker. When treating hypertension, anti-inflammatory medicine treatment needs to be } \\
\text { endorsed to successfully treat complaints and increase the communal and psychosomatic status of the patient. }\end{array}$ \\
\hline
\end{tabular}

\section{INTRODUCTION}

Hypertension or high blood pressure, which is also called arterial hypertension, is a long-lasting therapeutic complaint in which the blood pressure is at a unswerving high level of $140 / 90 \mathrm{mmHg}$ [1]. This ailment can be kept in control by changing one's dietary and lifestyle habits. Important changes in lifestyle that can bring about some degree of relief from this disease include weight loss, reduction in smoking, healthy diet, reduction in sodium intake, regular exercise, and limited alcohol consumption [2].

Sometimes, however, the disease becomes so chronic that simply incorporating these changes into one's life does not bring desired results [3]. In such cases, drug treatment is usually employed. Numerous classes of drugs are used for this purpose. They include ACE (Angiotensin Converting Enzyme) inhibitors, ARB (Angiotensin Receptor Blockers) drugs, diuretics, calcium channel blockers, alpha-blockers, and peripheral vasodilators [4]. Commonly used drugs for this purpose are Beta-blockers [5]. These drugs provoke the sympathetic nerve stimulus or circulating catecholamines at beta-adrenoceptors that are broadly disseminated all through body systems. $\beta 1$ - receptors are leading substances in the heart and kidney while $\beta 2$-receptors are chiefly present in other organs like the lungs, peripheral blood vessels as well as skeletal muscle. Obstructing $\beta 1$ - receptors in the sinoatrial node decreases heart rate. This is called negative chronotropic effect.

Likewise, barring $\beta 1$-receptors in the myocardium drops the contractility of heart muscles. This phenomenon is called negative inotropic effect [6].

Atenolol is a specific $\beta 1$ cardio-selective adrenoreceptor blocking agent. Not unlike the other medications, atenolol can cause some consequences as well. Most of these are expected to be inconsequential and exist only for a shorter period of time [7]. Nevertheless, some may necessitate medicinal care such as stomach upsets like constipation, indigestion, parched mouth, diarrhoea, modification in taste, sluggish or uneven heartbeat, giddiness, intestinal discomfort, nuisance, buzzing in the ears, glitches with vision, dry eyes, blocked nose, hallucinations, skin sensitivity, icy extremities and amplified hair damage [8]. However, if this drug is suddenly terminated, it becomes very problematic. There have been some reported cases where people have developed chest pain, heart attack, and irregular heartbeat. The potential risk of the development of acute pancreatitis has also been observed in some cases [9]. This condition involves the sudden inflammation of the pancreas that can have lethal side effects and extraordinary death rate even after cure $[10,11]$. Our following study is based on identification of risk of acute pancreatitis which may occur with different doses of atenolol in Pakistani population.

\section{MATERIALS AND METHODS}

\subsection{Sampling}

Patients were recruited from Punjab Institute of Cardiology Lahore (PIC). A total of 74 patients of different ages suffering from hypertension were selected after taking their complete medical history and divided into 2 groups ( $n=37)$; patients receiving atenolol as antihypertensive drug, patients administered combination treatment for hypertension based on severity and grade of disorder and compared with control group (healthy) Physical examinations were also carried out and complete records were maintained. All the combination and supportive medicines taken by the patients were noted. Random sampling technique was employed. Patients were administered their respective hypertensive medicine prior to sampling. However, patients experiencing hepatitis and any other concomitant disorder were excluded as patients were on multi drug therapy.

\subsection{Sample Analysis}

Human C-Reactive Protein (CRP) ELISA Test Kit was used. During this method each sample was permitted to achieve the room temperature. The latex was lightly mixed to dissolve the constituent parts. A bead of fullstrength serum was positioned on the test slide via the disposable pipette. A droplet of latex was positioned next to the drop of the serum. Using the alternative end of the pipette, the reagent and serum sample were spread above the complete zone of the test circle. The test slide was lightly slanted forwards approximately once every two seconds for two minutes. Positive and negative controls were also incorporated at consistent intervals. At the end of the test, the test slide was washed by means of distilled water and desiccated.

\subsection{Statistical analysis}

All the observations were tabulated and expressed as mean \pm standard error. Statistical analysis was carried out by using SPSS version. 22 (Statistical Package for the Social Sciences). T-test was applied to compare the difference between two variables. The level of probability was $\mathrm{p}<0.05$ [12].

\section{RESULTS AND DISCUSSION}

$\beta$-blockers are the major class of drugs for hypertension and due to their improved efficacy, they are mostly prescribed by physicians to hypertensive population. They are also used in different combinations of antihypertensive medications on the foundation of harshness of illness and complaint of patients. CRP levels of 37 hypertensive patients taking $\beta$ blockers alone were tested, the results obtained are described in Table 1 and Figure 1. 
Table1: Distribution of Hypertensive group on the basis of CRP value

\begin{tabular}{|llcccl|}
\hline Sr. No & Drug Class & $\begin{array}{c}\text { High } \\
\text { CRP }\end{array}$ & $\begin{array}{l}\text { Low } \\
\text { CRP }\end{array}$ & $\begin{array}{l}\text { Total Patients } \\
\text { CRP }\end{array}$ & \begin{tabular}{l} 
Parameter \\
\hline 1
\end{tabular} \\
2 & Beta-Blockers & 12 & 25 & 37 & $\begin{array}{l}\text { Reference range } \\
(0.3-0.8 \mathrm{mg} / \mathrm{dl})\end{array}$ \\
& $\begin{array}{l}\text { Combination } \\
\text { Medicines }\end{array}$ & 7 & 30 & 37 & \\
\hline & Total & 19 & 55 & 74 & \\
\hline
\end{tabular}

\section{Hypertenisive patients having High and Low CRP}

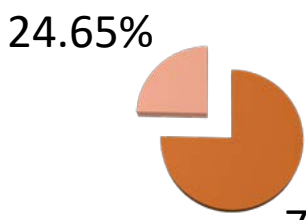

\section{Low \\ High}

$75.34 \%$

Figure 1: Population (75.34\%) appeared with lower value of CRP by using beta-blocker, while $24.64 \%$ population showed high value of CRP

Beta blocker therapy (atenolol) was administered to 37 patients, out of which 25 patients appeared with low CRP (C-reactive protein) values depicting its anti-inflammatory action, while 12 patients exhibited high value of CRP depicting strong effects of beta blocker in reversing inflammatory condition. The effect of beta-blocker on 12 patients who did not appear with stable condition can be contributed to under-dosage of beta blocker in those patients. Around $50 \%$ of our study population was administered with $\beta$-blockers. B-blockers significantly decreased the levels of CRP of test population [13]. As we know that hypertension is also associated with inflammation so antihypertensive medication also has anti-inflammatory effects. These observations are in synchronise with the study of a researcher who enrolled 49 patients in their study to check effects of atenolol in decreasing cardiovascular ailment as well as levels of CRP. Moreover, a group researcher also concluded that C-reactive protein is a significant risk factor for coronary artery disease, and that betablockers lower the levels of CRP [14]. Furthermore, there are a study also stated beta blockers such as metoprolol is a useful addition in lowering down CRP level.

Table 2: CRP level among different groups (Mean \pm SE)

\begin{tabular}{|ccc|}
\hline Sr. No & Groups & CRP \\
\hline 1 & Healthy control $(\mathrm{n}=25)$ & $0.49 \pm 0.02^{\mathrm{c}}$ \\
2 & Beta blocker (atenolol) $(\mathrm{n}=37)$ & $16.60 \pm 4.82^{\mathrm{a}}$ \\
3 & $\begin{array}{c}\text { Combination medicines along } \\
\text { beta-blockers }(\mathrm{n}=37)\end{array}$ & $9.23+3.72^{\mathrm{b}}$ \\
& & \\
\hline
\end{tabular}

In the present study, patients were also administered several combinations of antihypertensive agents randomly on the base of harshness of the disease and reaction upon therapy. The CRP levels of 37 patients who were taking combination antihypertensive drugs, based on grade and severity of disorder were tested. Combinations like statin, ACE inhibitor, diuretics, calcium channel blocker, AT2 receptor blocker were used. All these combinations proved to be highly efficacious in reversing inflammation. About 30 out of total 37 patients appeared with normal value of CRP while only 7 showed high levels of CRP. Again the 7 patients who appeared with high levels of CRP can be contributed to under dosages of these combinations.

Combination of calcium blocker statin ACE inhibitor was administered and their CRP level were analysed to check the probability of any sign of inflammation secondarily due to hypertension. CRP level with class of calcium blocker along with beta blockers gave mean value of 0.48 that fall under normal level depicting no effect of calcium blocker upon level of CRP. Evidence of same results can be taken from a research done by demonstrated that levels of high-sensitivity CRP decreases after treatment with antispastic agents.

Hypertensive patients were also administered with combination of statin in conjunction with beta blockers. The mean value for this group was 0.60 and statin profoundly decreased the levels of CRP. The same results were reported by a group researcher the CRP levels become significantly lower in patients with CVS disorder when treated with statins [15]. Furthermore, a research also suggested that statin is responsible for effectively lowering down levels of CRP in the duration of 14 days regardless of their property of lowering down lipids.

Our study population was also administered combination of ACE inhibitor and calcium blocker along with beta-blockers and the mean value for this group was found to be 0.55 , thus strongly depicting higher potential of this regimen in reducing higher levels of CRP [16]. Another study reported that beta-blocker ACE inhibitors are highly associated with lowering down CRP level [17].

In current study, the patients were administered with many combinations with beta-blocker and their results showed that these combinations significantly lower the CRP level in hypertensive patients [18]. The research conducted by a researcher demonstrate that antihypertensive such as beta blockers, ACE inhibitors, anti-diabetic agents, ARBs, antiinflammatory agents, vitamin $\mathrm{E}$, and beta-adreno-receptor antagonists decrease serum or plasma levels of CRP [19].

The beta-blockers and all antihypertensive medications have high potential in decreasing inflammation due to hypertension [20]. In this study, as patients were administered with beta blockers and combinations as well, and both of these have high potential in decreasing inflammatory disorder secondarily due to hypertension, so can be seen in our study as 55 patients expressed stable value of CRP and evidences for these results can also be taken from several studies done in different times.

In our study population random patients were selected from Punjab institute of cardiology and we also wanted to record gender statistics of Pakistani population which is affected from hypertension. So, we found that females have high potential of developing hypertension, as $53.42 \%$ of random diseased population were females while $46.57 \%$ were male.

\section{CONCLUSION}

This study was designed to check the efficacy of antihypertensive in decreasing ailment as well as reducing risk of inflammation which develops secondarily due to hypertension. We conclude that antihypertensive drugs specifically also minimize the inflammation associated with hypertension but not completely, as inflammation was reversed only in $67.5 \%$ population who were using beta-blocker. When treating hypertension, anti-inflammatory medicine treatment must be suggested to successfully treat disorders and escalate the communal and psychological status of the patient. Moreover, new antihypertensive therapies should be exposed with increased efficacy and additional characteristics in reducing risk of inflammatory pathology. Furthermore, patients coming with hypertension must also be examined for any inflammatory sign so that the treatment should be administered accordingly.

\section{ACKNOWLEDGMENTS}

Authors are thankful to Punjab Institute of Cardiology, Lahore for their cooperation to conduct this study trail.

\section{REFERENCES}

[1] Kannel, W. B. 1996. Blood pressure as a cardiovascular risk factor: prevention and treatment. JAMA, 275, 1571-6,

[2] Kearney, P. M., Whelton, M., Reynolds, K., Muntner, P., Whelton, P. K., and He, J. 2005. Global burden of hypertension: analysis of worldwide data. The Lancet, $365,217-223$.

[3] Chobanian, A. V., Bakris, G. L., Black, H. R., Cushman, W. C., Green, L. A., Izzo, J. L. 2003. National High Blood Pressure Education Program Coordinating Committee, The Seventh Report of the Joint National Committee on Prevention, Detection, Evaluation, and Treatment of High Blood Pressure. The JNC 7 Report, 289, 2560.

[4] Gewurz, H., Mold, C., Siegel, J., and Fiedel, B. 1982. C-reactive protein and the acute phase response, Advances in Internal Medicine, 27, 345-72.

[5] Sung, S. Y., Yechiam, O., and Tatiana, L. 2010. Recent Trends in the Prevalence of High Blood Pressure and its Treatment and Control 19992008. NCHS Data Brief, 48, 1-8.

[6] Langer, S. Z., Cavero, I., Massingham, R. 1980. Recent developments in noradrenergic neurotransmission and its relevance to the mechanism of action of certain antihypertensive agents. Hypertension, 2, 372-82.

[7] Carretero, O. A., and Oparil, S. 2000. Essential hypertension. Part I: Definition and etiology. Circulation. 101, 329-35. 
[8] Hashmi, S. K., Afridi, M. B., Abbas, K., Sajwani, R. A., Saleheen, D., Frossard, P. M., and Ahmad, U. 2007. Factors associated with adherence to anti-hypertensive treatment in Pakistan. PLoS One, 2, 1-7.

[9] Miller, F. H., Keppke, A. L., Dalal, K., Ly, J. N., Kamler, V. A., and Sica, G. T. 2004. MRI of pancreatitis and its complications: part 1 , acute pancreatitis. AJR. 183, 1637-44.

[10] Frossard, J. L., Steer, M. L., and Pastor, C. M. 2008. Acute pancreatitis. The Lancet, 371, 143-152.

[11] Brown, D., Baillargeon, J. D., Hughes, M. D., and Banks, P. A. 2002. Can fluid resuscitation prevent pancreatic necrosis in severe acute pancreatitis? Pancreatology, 2, 104-107.

[12] Steel, R. G. D., and Torrie, J. H. 1993. Principles and Procedures of Statistics. A Biometrical Approach. 2nd ed., McGraw-Hill Book Co., New York, NY.

[13] Morley, J. J., and Kushner, I. 1982. Serum C-reactive protein levels in disease. Annals of the New York Academy of Sciences, 389, 406-18.

[14] Nicholas, P. J., Brian, G. K., Ian, V. H., and Nicholas, H. B. 2002. Betablockers are associated with lower C-reactive protein concentrations in patients with coronary artery disease. The American Journal of Medicine,112, 269-274.

[15] Takeda, T., Hoshida, S., Nishino, M., Tanouchi, J., Otsu, K., and Hori, M. 2003. Relationship between effects of statins, aspirin and angiotensin II modulators on high-sensitive C-reactive protein levels. Atherosclerosis, $169,155-8$.

[16] Johnson, C., and Lévy, P. 2010. Detection of gallstones in acute pancreatitis, when and how. Pancreatology. 10, 27-32,

[17] Keim, V., Teich, N., Fiedler, F., Hartig, W., Thiele, G., and Mossner, J. 1998. A comparison of lipase and amylase in the diagnosis of acute pancreatitis in patients with abdominal pain. Pancreas. 16, 45-9.

[18] Lewis, M. J., Jones, D. M., Dart, A. M., and Henderson, A. H. 1984. The psychological side effects of acebutolol and atenolol. British Journal of Clinical Pharmacology, 17, 364-366.

[19] Munsell, M. A., and Buscaglia, J. M. 2010. Rate of hydration in acute pancreatitis. Journal of Hospital Medicine, 5, 241-250,

[20] Scaglione, M., Casciani, E., Pinto, A., Andreoli, C., Vargas, M., and Gualdi, G. F. 2008. Imaging assessment of acute pancreatitis: a review. Seminars in Ultrasound, CT, and MRI, 29,322-340. 83, 1637-44. 